\title{
Index des lieux et des personnes
}

Abān al-Lāhịiqī, poète abbasside 183, 187

Abbadides, dynastie de Séville 87

'Abbās b. Nāṣih, poète andalou 93

Abbassides, dynastie 34, 42, 59, 97, 172

'Abd al-Bașīr, haut fonctionnaire mamelouk 105

'Abd Allāh, roi berbère de Grenade 87

'Abd al-Qāhir al-Bag̉dādī, savant shafiite 188

'Abd ar-Rahmān I ${ }^{\text {er }}$, émir omeyyade de Cordoue 75-76, 84, 97-98

'Abd ar-Rahmān II, émir omeyyade de Cordoue 86, 127-128

'Abd ar-Raḥmān III, calife omeyyade de Cordoue 75-76, 79-82, 86, 88, 98, 128, 211

Abdellatif, Rania 17, 208

'Abla, cousine de 'Antara 77

Abou Ghosh, église 52

Abraham, patriarche biblique 63

Abraham Bar Hiyya, mathématicien et astronome juif 132

Abraham Bondavin d'Avignon, médecin juif $160,163-166$

Abraham, époux de Sarah de Saint-Gilles 161

Abraham Fera, homme d'affaires juif 104

Abraham Ibn Daud, chroniqueur juif andalou 96

Abraham Ibn Ezra, savant juif andalou 87-88, 97

'Abs, tribu arabe 77

Abū al-Mahšš, poète andalou 98

Abū Bakr b. Zakariyā' ar-Rāzī 152-153, 156,162

Abu Bakr Ibn al-'Arabī, jurisconsulte andalou 97

Abū Bakr, premier calife de l'islam 170

Abū Ḥāmid al-Ġarnāțī, voyageur 131

Abū Ishāq at-Tūnisī, jurisconsulte 62

Abū Ish̄āq b. Šahrām, ambassadeur 34

Abū Ma šar, mathématicien et astrologue persan 51

Abū Nașr al-Manāzī, poète 35

Abū Nuwās, voir al-Hasan b. Hanī

Abū Sa'̄ì Bahadūr 132

Abū Šāma, chroniqueur syrien 61
Abū 'Ubayda b. al-Ğarrāh, gouverneur de Damas 170

Abū'l-Fidā', géographe et historiographe syrien 133

Abū'l-Husayn Muhammad b. 'Abd alWahhāb, source d'information d'Ibn Hawqal 125

Abū'l-Qāsim Halaf az-Zahrāwī, médecin andalou 161

Abulafia, David 151

Academi, entreprise de sécurité 200

Acre 52-54, 112

Adélard de Bath, mathématicien et traducteur 51,64

Aden 100

Adhémar de Chabannes, chroniqueur de Limoges 60

Afrique 122, 136-137, 140-142, 144; - du Nord 131, 136, 138-139, 141, 148, 150, 155

Aḥmad b. Muḥammad ar-Rāzī, chroniqueur andalou 123

Aḥmad b. Yazīd al-Assadī, qāộ̄ de Damas 169

Ahmadinejad, Mahmoud 83

Aix-en-Provence 158-159

Aix-la-Chapelle 39, 41-43, 127

al-'Âdil, sultan ayyoubide 174

al-Andalus 15-16, 62, 64, 74-76, 79, 82, 84, 86-90, 93-98, 122-123, 127-128, 206-208, 210-211

al-Aqsirā'̄ $\overline{1}$, juriste hanafite 176

al-Ašraf Barsbay, sultan mamelouk 112

al-Azmeh, Aziz 209

al-Azraqī, historiographe 176, 179

al-Bakrī, géographe andalou 124-125, 128

Albert d'Aix, historiographe 25, 66

al-Biqā̄î̀, Ibrāhīm b. 'Umar, chroniqueur mamelouk 116-117

Albubather, médecin et astrologue persan 153

Alep 34, 54, 131

Alexandre, roi de Macédoine 37

Alexandre d'Aphrodisie 158

Alexandre VI, pape 158

Alexandrie 94, 100-108, 137, 196

Alfanus de Salerne, archevêque 38, 148 
Alfonso, Esperanza 85, 96

al-Ġazzāl, ambassadeur omeyyade andalou 128

Algéciras 93

al-Hakam II, calife omeyyade d'alAndalus 128

al-Hākim, calife fatimide 26

al-Hamdān̄̄, géographe 123

al-Hārit b. Bazi', commandant omeyyade andalou 76

al-Hasan b. Han̄i, poète arabo-persan (=Abū Nuwās) 75, 78

al-Hatị̂ al-Bag̉dādī, chroniqueur 34

al-Himā 98

al-Himyarī, géographe maghrébin 123 , 130,133

al-Hunkar/al-Hunqar 131

al-Hwarizmī, géographe persan 122, 129

'Alī b. al-'Abbās al-Mağūsī, médecin persan 149-150, 156, 213

'Alī b. Muğāhid, roi de la taïfa de Denia 65-66, 68, 74, 208

'Alī, eunuque aghlabide 58-59

al-Idrīsī, géographe 128-131, 133-134, 138,142

Alissona, femme de Jean Davin 167

Allemagne 54, 56, 127, 132-133, 191, 193

al-Mağūsī, voir 'Alī b. al-'Abbās

al-Mahdī, calife abbasside 34

al-Manșūr, calife abbasside 42, 126

al-Maqqarī, historien maghrébin 123

al-Marwāzī, astronome et géographe persan 125,131

al-Mas' ūdī, géographe 122, 125, 128

Almeria 90

Almohades, dynastie 15, 96-97

Almoravides, dynastie 15, 88, 96

al-Muktafī bi-llāh, calife abbasside 59

al-Muqaddasī, géographe 97

al-muša'midūn 66-68

al-Mustanșir, calife abbasside 53

Alpes 155

Alphonse VI, roi de León et Castille 88

al-Qalqašandī, sécretaire mamelouk 130 , 133

al-Qazwīnī, cosmographe persan 127, 131

al-'Udrīi, savant andalou 127

al-'Umarī, Ibn Faḍl Allāh, sécretaire mamelouk 130, 132-133

al-Walīd b. 'Abd al-Malik, calife omeyyade 169-170, 172, 178

al-Watīiq, calife abbasside 125
Amalarius de Metz, émissaire carolingien $42-43$

Amalfi 51

Amalfitains $50-51$

Ambassadeurs 31-47

amīr al-mu'minīn 24

Anastase le Bibliothécaire, émissaire carolingien 36,43

Anatolie 15

Andalous 84, 90, 98

Andalousie arabe 84

Andrea Alpago, médecin et arabisant italien $154-156$

Andrea da Como, marchand génois 104 105

Angelino Dalorto, cartographe majorquin 139

Angelino Dulcert, cartographe majorquin 139-140, 144

Angelo Michiel, marchand vénitien 104 105

Angleterre 70, 120, 129, 195-196, 198, 202, 214

an-Nāșir li-dīn Allāh, voir 'Abd arRahmān III

an-Na'ūra 79

'Antara b. Šaddād, poète préislamique 77, 79

Anthol Samson, homme d'affaires juif 163

Antioche 51, 147, 153, 168, 213

Antonio Doria, amiral de France 195, 201

Apennin 49, 54

Apollonia 138

Aquilée 129

Arabes $62-63,75-78,147,151$

Arabie 89, 92, 98

Aragon 88, 196, 215

Archives d'État de Venise 118

Aristote 51, 152, 162, 214

Arles 159-161

Armée chypriote 53

Arménie 194

Arméniens 53-54

Arnaud de Villeneuve 162

Aron, prophète israélite 94

ar-Rāzī, Abū Bakr b. Zakariyā', médecin persan 149-150, 153, 162

ar-Rāzī, Ahmad b. Muhammad, chroniqueur andalou 123

ar-Rūm 35

Arsuf 52

Artisans byzantins 171

Ašğa', tribu arabe 75 
Asie 122, 144; - centrale 15, 185, 215;Mineure 68, 132, 196

aṣ-Șālih Nağm ad-Dīn Ayyūb, sultan ayyoubide 60

aš-Šām 97, 172

Astrologues 143, 181

Asturies 76, 128

Athanase, saint 51

Athos 50-51

Atlantique 133, 136, 142

Atrani 51

Avares 125

Averroès 152-153, 158, 162

Avicenne 150, 152-153, 155, 158, 162

Avignon 160-161, 163

Aviva, Doron 97

Awrūfa 123

Ayalon, David 111

Aycardet André, pêcheur 164-165

Ayyoubides 132-133, 172

Bagdad 29, 33-34, 42, 122, 124-126, 131, $153,185,191,211$

Balaba de Janua 132

Balard, Michel 15, 209, 213

Balkans 15

Banū Hafșūn 78

Banū Hilāl 15

Banū Qasī 75-78, 82-83, 210

Banū Sulaym 15

Banū Tư̛̆̀ib 78

Banzart 137

Baratier, Édouard 159

Barkaï, Ron 97

Barlaam 180-191, 215

Barthélemy, Louis 159

Basile de Césarée, Père de l'Église 38

Basilique de la Nativité 52

Bāšqird 131

Basra 187

Bassin de la Volga 130; - méditerranéen 193

Baybars, sultan mamelouk 52

Bayonne 129

Bayt al-māl 172

Bayt al-Maqdis 97

Belin della Porta 104

Bella, grand-tante de Bonjuson 160

Belvoir, château de 52

Bencheikh, Jamal Eddin 90

Benedetto Zaccharia, amiral de France 195
Benevento de Vérone, voir Filippo di Malerbi 101

Benhima, Yassir 212-213

Benjamin Arbel 118

Benjamin de Tudèle, voyageur juif andalou 127,158

Benoît, saint 51

Berbère 75, 78

Bernard de Gordon, médecin à Montpellier 162

Bernard le Moine, voyageur 23

Berthe de Toscane, épouse du margrave Albéric II 59, 64

Béthel 91

Bethléem 52

Biagio Dolfin, consul vénitien à Alexandrie 101-102

Bibliothèque nationale de France 152, 154

Bilād aššsām 172

Bilawhar, voir Barlaam

Bizerte 137

Blackwater, entreprise de sécurité 200

Bohême 127

Boleslas I ${ }^{\text {er }}$, roi de Pologne 127

Bondavin de Draguignan, prêteur juif marseillais 159

Bonet, habitant juif d'Avignon 163

Bonet Astruc de Lattes, médecin juif 158

Bonfils, emprunteur d'un manuscrit médical 162

Bonjuson Bondavin, talmudiste 159-160

Bordeaux 127, 131-132

Borrian, famille de 158

Bosone da Gubbio, poète 157

Bosphore 34, 36-38, 40-41

Bouddhistes 215

Bougie, douane de 210

Brentjes, Sonja 16, 210

Bretagne 123, 129

Bruno de Segni, évêque, abbé de MontCassin 51

Būḍāsaf, voir Josaphat

Buddha 180-182, 185-186

Bulgares 15, 122, 125, 130-132, 209; - de la Volga $125,128,132-133$

Burdbak al-Ašrafī, secrétaire du sultan mamelouk Ināl 116-117, 119

Burğān 125

Burgundio de Pise, émissaire pisan 38, 51

Byzance 15, 31, 34-36, 38-40, 43, 46-47, 51, 126, 169, 194, 204, 206, 209, 211

Byzantins 35, 41-43, 46, 122, 125, 170171,203 


\section{Caffa 54}

Caillé, Jean-Pierre 41

Caire, Le 53, 100-108, 111, 114-116, 128, $132,153,187,210-211$

Califes abbassides 33

Cappadoce, province romaine 68

Captifs 28, 111

Captives franques en al-Andalus 208

Carcassonne 163

Carlo Grimaldi, amiral de France 195, 201

Carlyle, Thomas 11

Carolingiens 41, 134

Carthage 148

Cartographes 136-146; - italiens 140;juifs de Majorque 137 ; - majorquins 141

Carzimasiens 64

Cassius, ancêtre des Banū Qasī 76

Castillan 129

Castille 88, 115, 214

Catalogne 132, 162, 197

Catherine de Courtenay, héritière de l'Empire latin de Constantinople 194

Caucase 126

Cercasso, famille de 118

Césarée 52-53

Chancellerie palermitaine 129

Charlemagne 12, 42-43, 124

Charles d'Anjou, roi de Sicile 152

Charles de Valois, comte de Valois 194 195, 203

Charles II, roi de France 160

Charles VI, roi de France 195, 204

Charlotte de Lusignan, reine de Chypre 115-117, 207

Château de Saone 52

Chesinos, fleuve imaginaire 141

Chiites duodécimains 189-190

Chio 49-50, 54

Chrétiens latins du nord de l'Espagne 212; - occidentaux 114; - orientaux 112, 114

Chrétienté 213;- latine 207, 213

Christ, Georg 16, 210

Christ, le 20, 22, 24, 80, 82

Chypre 16, 23, 54, 111-119, 207

Cidellus, voir Joseph ha-Nasi Ferruziel

Citadelle du Caire 112

Cités-États italiennes 14-15, 190

Ciutat de Mallorca 141

Coimbra 129

Colonies amalfitaines 48; - génoises 48, 54 ; - d'Orient 49
Communauté géorgienne de Jérusalem 189-190; - juive de Marseille 158; monastique grecque de Rome 36; vénitienne d'Alexandrie 104, 108

Communautés chrétiennes de Damas 28; juives en Europe orientale 128

Commune de Gênes 49-50

Comptoirs génois d'Orient 49

Comté de Tripoli 52

Constance II, empereur romain 70

Constantin l'Africain, traducteur arabisant 38, 148-150, 155-156, 213

Constantin V, empereur byzantin 43

Constantinople 34-38, 40-42, 50-51, 125, 128, 171, 194, 196, 203, 206

Consul vénitien à Alexandrie $101-103$; - à Damas 154

Consuls de Montpellier 201

Contado (Ligurie) 49

Cordoue 61, 66-68, 73, 75-76, 78, 81, 84, 87-88, 97-98, 128, 153, 171, 208-211

Corse 54

Coulet, Noël 157

Coumanie 129

Cour abbasside $59 ;-$ byzantine $33 ;-$ de Frédéric II 152; - germanique 38; impériale germanique 37 ; - de Kairouan $149 ;-$ mamelouke 100,114 , 207; - normande de Sicile 38

Couronne d'Aragon 38

Cours catholiques 145

Couvent amalfitain du Mont-Athos 50;Sainte-Marie-des-Amalfitains à Constantinople 51

Crac des chevaliers, château 52

Cracovie 127, 129

Crema 64

Cresques Abraham, cartographe juif majorquin $140,144-146$

Creswell, Keppel A. C. 173

Crète 54

Croisés 49, 96-97, 133, 173, 177

Cypriotes 113, 115, 117

Dalché, Gautier 141

Dalorto, voir Angelino Dalorto

Damas 28, 33, 76, 98, 113, 118, 154, 168, 170-171, 176, 208-209

Damiette 132-133

Dante Alighieri 157

Danube 68

Dār al-Islām 206

David, roi israélite 84,170 
David Kokhabi, talmudiste 158

Davin de Bourgneuf 161

Dejugnat, Yann 16, 206

Delaville Le Roulx, Joseph Marie Antoine 192, 197

Denia, taïfa de 60, 65, 74, 206

Désert 27,96, 98

Déserts d'Arabie 98

Desiderius, abbé de Mont-Cassin 148, 155

Destroiz de Marroch 202

Devins 143

Diaspora vénitienne 16

Didier du Mont-Cassin 38

Dieu 20, 43, 62, 92-93

Dieulocrescas Jossé Roget, médecin juif 164-166

Dioscoride, médecin grec 51, 211

Diya' ad-Dīn 'Īsā al-Hakkārī, gouverneur ayyoubide de Jérusalem 174, 178

Djanibeg, Khan de la Horde d'or 144

Dniepr 141

Doge de Gênes 195

Dolfin, famille de 104

Domaine hispano-maghrébin 213

Dôme du Rocher 52, 168, 173-179

Domenicus, fils de Ğān Balāt 118

Dominicains 60

Dominique Doria, source d'information d'al-'Umarī 132-133

Don 141

Donjons normands 52

Donzel-Verdeil, Chantal 16

Doria, famille de 201-202

Doukas Limpidaris, fonctionnaire byzantin 195

Dozy, Reinhart 124

Drocourt, Nicolas 15, 211

Druzes 189

Dubler, César 129

Duc de Bourbon 196

Ducène, Jean-Charles 16, 209

Dulcert, voir Angelino Dulcert

Dulciette, fille de Jean Davin 166

Dumézil, Bruno 13

Dunash Ben Labrat, poète juif andalou 89

Durante, fille de maître Ferrier Marvan 166

Écosse 54

Édesse 97

Édom 95-96

Église d'Abou Ghosh 52; - de l'Annonciation 53; - de la Crucifixion
52 ; - de Lydda $52 ;$ - de Ramla $52 ;-$

Sainte-Anne 52;-Sainte-Marie

d'Antioche 171-172; - Sainte-Marie-

des-Teutoniques 52; - Sainte-Sophie

43; Saint-Jean-Baptiste 168, 170, 172-

173, 178; - Saint-Marc 51; - Saint-

Paul-hors-les-murs 51

Églises du Caire 114; - byzantines 52

Égypte 15-16, 23, 27, 90, 94-95, 100, $132,141,176,206,210-211$; - mamelouke 132

Égyptiens 123

Eichstätt 23

Elvira, sœur de Sancho I ${ }^{\text {er }} 81$

Embriaci, famille de 49

Émèse, voir Hims

Émigré juif à Alexandrie 137

Émirs mamelouks 116-117

Émissaires de Charlotte, reine de Chypre 117

Emmanuel de Rome, adaptateur de l'œuvre de Dante en hébreu 157

Empereur byzantin 171-173, 202-203;grec 204

Empereurs romains 63

Empire abbasside 124 ; - byzantin 31,34 , 41, 44, 50, 125-126, 134, 147, 203, 206, 211;-germanique 196; - latin de Constantinople 194; - mamelouk 100, 192; - ottoman 192; - romain 68-69, 168 ; - romain d'Orient 36 ; - sassanide 147

Ennemi chrétien 176

Éphèse 34

Esclaves berbères 62 ; - francs 62 ;galiciens $62 ;-$ militaires 111

Espace arabo-musulman 207; - latinochrétien 207;-méditerranéen 15,207; -mésopotamien 192;-micrasiatique $192 ;$ - syro-égyptien 192

Espagne 53, 64, 72, 76, 84, 96-97, 124, 127, 129-130, 153, 156, 207; - chrétienne 96;- musulmane 127, 134, 207, 211;-reconquérante 206

Esposito, Anna 158

États francs de Syrie-Palestine 48, 51;latins d'Orient/de Syrie-Palestine 48, 51-54, 96-97

Étienne de Pise/Étienne d'Antioche 51, $150,156,213$

Étoile 158

Euclide, mathématicien grec 51, 158

Eugenius, amiral de Sicile 151 
Euphrate 141

Eurasie 122, 134

Europe 16, 100, 106, 122-134, 147, 214, 216 ; - carolingienne 127,134 ; - centrale 125,$129 ;-$ chrétienne 48,111 , 207 ; - continentale 124 ; - de l'Est 122 ; - latine 100, 193, 197, 210-211, 214;du Nord 127, 155; - occidentale 1314, 126, 130; - orientale 125, 131-134; - du Sud 155

Européens 122, 130, 134; - de l'Ouest 209

Euthymios Hagiorite, moine géorgien, abbé du couvent géorgien du MontAthos 190

Faculté de médecine de Montpellier 162

Famagouste 53-54, 112

Farağ ben Sālim, traducteur juif de Sicile 152-153

Farragut, voir Farağ ben Sālim

Fatimides 15, 26, 144

Feres Mamaluco, partisan de Jacques II de Lusignan 118

Ferrare 132

Ferrier Marvan, chirurgien juif 160-161, 164-166

Fierro, Maribel 16, 90, 210

Filippo di Malerbi 16, 100-109, 211

Flandre, la 202

Flatro, famille de 115-116

Flood, Finbarr Barry 175

Florence 210;-concile de 210

Forster, Regula 17, 215

Forteresse de Thessalonique 195

Fortifications 111

Foucher de Chartres 61

Français 133, 197-198, 202

France 54, 70, 126-127, 129-131, 162, 192-205, 211, 214; - du Nord 184;du Sud 157

Franchinus, voir Farağ ben Salim

Franciscains 133

François d'Assise 27

Francs 52, 117, 119, 122, 128, 174, 177$178,209,212$

Frédéric $\mathrm{I}^{\mathrm{er}}$ Barberousse, empereur germanique $41,64,133$

Frédéric II de Hohenstaufen, empereur germanique 151-152, 155

Frères mineurs 27

Frontière 207, 210, 213

Fulda 127
Galice 81,123

Galatie, province romaine 68

Galien 123, 147, 162

Ğān Balāt, Mamelouk, partisan de Jacques II de Lusignan, gouverneur mamelouk de Jérusalem, vice-roi mamelouk de Damas 118-119

Ğarmī, auteur d'un livre sur les Byzantins 125

Garnison de Famagouste 54

Garulo, Teresa 89

Gascon 129

Gaule 124

al-Ğayhānī, géographe de l'Asie centrale 125

Gênes 49-50, 54, 112, 132-133, 144, 195

Gennadius de Marseille, écrivain romain tardo-antique 12

Génois 49-50, 53, 195, 201-203

Gentils 93

Geoffroy, abbé de Saint-Martial de Limoges 60

Géographes arabes 209

Georgious Boustronious, chroniqueur cypriote 117,119

Gérard de Crémone, traducteur arabisant $39,143,154,156,214$

Germanie 123

Gérone 128

Géza II, souverain hongrois 129

Ghur Kerman 131

Gibelet, famille de 49, 54

Gimaret, Daniel 182-183, 186-187

Gioan Cercasso, voir Ğān Balāt

Giovanni du Mont-Cassin, enlumineur 153

Girolamo Ramusio, médecin du consulat vénitien à Damas 154-156

Giustiniani 50

Godmar, évêque de Gérone 128

Golfe Persique 142

Gómez, García 90

Goths 68-70

Gouguenheim, Sylvain 214-215

Gouverneur mamelouk de Jérusalem 118

Grèce 183,204

Grecs 41, 51, 53-54, 194, 204; - anciens 34

Grenade $84,87-88$

Grenadins 213

Grimaldi, famille de 199-200

Guadix 88

Guibert de Nogent, chroniqueur 25-26

Guichard, Pierre 17 
Guillaume de Tyr, chroniqueur 52

Guillaume I ${ }^{\mathrm{er}}$ le Mauvais, roi normand de Sicile 38, 151

Guillaume II le Bon, roi normand de Sicile 151

Guillaume Mathole, barbier chrétien 160

Guillaume Pierre Lascar, viguier royal 167

Ğulbān, jeunes Mamelouks 116

Hafṣ b. Albar al-Qūțī, traducteur des Psaumes en arabe 61, 123

Halitgaire de Cambrai, évêque, ambassadeur à Byzance 42

Halle 182, 187

Haly Abbas, voir 'Alī b. al-'Abbās alMağūsī

Harem 29

Hāriğiyya 77

Hārūn b. Yaḥyā, captif arabe à Byzance 125

Hasan, frère de 'Alī b. Muğāhid 65

Hasday b. Šaprūt 88, 127-128, 211

Hațtīin 11, 27

Hauts fonctionnaires mamelouks 102-105

Hazars 128

Henri Aristippe, chancelier de

Guillaume I ${ }^{\text {er }}$ de Sicile 38-39

Henri II, empereur saxon 74

Hermoygius, évêque de Tuy 80

Héros 10

Heyberger, Bernard 16

Hillenbrand, Carole 174-175

Hillenbrand, Robert 176

Himṣ 24

Hippo Regius 139

Hippocrate 123, 147

Hišām b. 'Abd ar-Raḥmān, émir omeyyade 98

Hongrie 129-131

Hongrois 15, 41, 122, 125, 128-129, 131, 209;- musulmans 131

Honoré d'Autun (Honorius Augustodunensis), géographe 141

Hôpital de l'Annonciade à Marseille 161; - des pauvres du Christ et du SaintEsprit 166; - du Saint-Esprit à Marseille 161

Hôpitaux 167

Horde d'or 132-133, 144

Hospitaliers 52, 113, 193; - de Saint-Jean de Rhodes 115

Hrotsvita de Gandersheim, poétesse ottonienne $80-81$
Huesca 70

Hugeburc, religieuse d'Eichstätt 23

Hugues Éthérien, théologien italien, fonctionnaire à la cour de Manuel Comnène 51

Humanistes 148

Humbert II de Vienne, commandant de l'armée chrétienne à Smyrne 196

Humphreys, Stephen 111

Hunayn b. Ishạāq, traducteur nestorien 59, 147,149

Huneberc, religieuse d'Eichstätt 23

Hurramī, voir Ğarmī

Hwārizm 126

Iancu-Agou, Danièle 157-158, 167

Ibn 'Abd al-Hakam, chroniqueur égyptien 58

Ibn 'Abdūn, jurisconsulte andalou 214215

Ibn al-'Arabī, mystique et poète andalou 99

Ibn al-'Atțāar, jurisconsulte andalou 62

Ibn al-Faqīh al-Hamadān̄ī, géographe persan 42,126

Ibn al-Ǧazzār, médecin à la cour de Kairouan 149

Ibn al-Hağğ, mudéjar sévillan expert en charpenterie militaire et navale 213

Ibn al-Hațīb, vizir de Grenade 65, 213

Ibn al-Qūțiyya, chroniqueur andalou 75

Ibn an-Nadīm, libraire de Bagdad 34, 183, 187

Ibn ar-Riğāl, astrologue 146

Ibn 'Asākir, chroniqueur de Damas 169171

Ibn Bābūya, chiite duodécimain 182, 186

Ibn Buțlān, médecin nestorien 152

Ibn Dihya, poète andalou 128

Ibn Ezra, famille de 87

Ibn Faḍlān, voyageur 125

Ibn Ġarsiyya, poète de la taïfa de Denia $62-63,66$

Ibn Ğazla, médecin irakien 153

Ibn Ğubayr, voyageur andalou 99

Ibn Hafăğa, poète andalou 89

Ibn Hawqal, géographe et voyageur 66, 125-127

Ibn Hayyān, chroniqueur andalou 79, 81, 127

Ibn Hazm, polygraphe andalou 76

Ibn Hūd al-Muqtadir, émir de Saragosse 66 
Ibn Hurradadbih, géographe persan 125126

Ibn 'Imrān, médecin à la cour de Kairouan 149

Ibn Qudaydār, šayh damascène 113

Ibn Rušd, philosophe andalou 152-154, 158,162

Ibn Rustah/Ibn Rusteh, géographe persan 125

Ibn Šaddād, chroniqueur ayyoubide 61, 175

Ibn Sa'īd al-Mag̉ribī, géographe 130-131, 133

Ibn Sīna, polygraphe persan 150,152 , 155, 156, 162

Ibn Šuhayd, voir Umayya b. 'Īsā b. Šuhayd

Ibn Tağrībirdī, historiographe mamelouk 114,116

Ibn Taymiyya, juriste hanbalite 177

Ibn Tibbon, famille de 152, 158, 162

Ibn Zaydūn, poète andalou 89

Ibn Zuhr, médecin andalou 153

Ibrāhīm b. Ya'qūb al-Isrā'î̀1̄̄ aṭ-Ṭurțūšī 126-127, 131, 209-210

Ihwān aṣ-ṣafā' 187-188

Îles anglaises 123

Ilkhanides 144

'Imād ad-Dīn al-Iṣfahānī, secrétaire de Șalāh ad-Dīn 174-175

Ināl, sultan mamelouk 115-116

Inde $100,180,185,190,207,215$

Innocent IV, pape 60

Iohannitius, voir Hunayn b. Ishāa

Iqbāl ad-dawla, voir 'Alī b. Muğāhid

Irak 185-186, 188, 190, 215

Iran $83,133,144,215$

Irène, sainte 51

Irlande 131

'Īsā b. Habīib an-Nağğār, source d'information d'Ibn Hawqal 125

Isaac ben Sheshet Barfat, talmudiste 159

Isaac Israeli, médecin juif 149, 162

Isaac, ambassadeur juif de Charlemagne 124

Ishāa b. Hunayn, fils de Ḥunayn b. Isḥāq, traducteur nestorien 59

Isidore de Séville 123-124, 141

Islam 31, 35, 40, 47, 204-205, 206, 208, $210,212,215$

Ismaéliens, chiites 189-190

Israël $88,91,95-96$

Italie $17,40,49,54,130,133,141,147$, 145, 153-154, 156-157, 211; - méri- dionale $15,38,51 ;-$ du Nord 38,213 ;

du Sud 51, 53, 148, 150

Italiens 131, 133, 195, 202

Itzhaki, Masha 89, 91, 94

Jacob ben Makhir, médecin juif 162

Jacob Bonacosa, traducteur juif de Padoue 153

Jacob de Lattes, lettré juif provençal 157

Jacquart, Danielle 159

Jacques de Billy, abbé de Saint-Michel de l'Herm 184

Jacques de Venise, traducteur vénitien 214-215

Jacques de Voragine, chroniqueur, archevêque de Gênes 184

Jacques Ferrand alias Galhart, apothicaire chrétien 165

Jacques II de Lusignan le bâtard, roi de Chypre 115-119, 207

Jaffa 52

Janus de Lusignan, roi de Chypre 112-116

Japon 180, 191, 215

Jean Algen, médecin chrétien d'Avignon 163

Jean Chrysostome, Père de l'Église 38, 51

Jean Damascène, Père de l'Église 38, 51, 190

Jean Davin, infecté par la lèpre 166

Jean de Gorze, émissaire ottonien à Cordoue 128

Jean de Neufbourg, médecin chrétien 166

Jean de Séville, mathématicien, traducteur 146

Jean II de Lusignan, roi de Chypre 115

Jean le Grammairien, émissaire byzantin $33,40,47$

Jean Monomaque, commandant de la forteresse de Thessalonique (?) 194 195

Jean Philagathos, ambassadeur ottonien à Constantinople 37

Jean Skylitzès, chroniqueur byzantin 33, 39

Jean Tzimiskès, empereur byzantin 37

Jean-Baptiste, saint 24, 168, 170

Jérôme, Père de l'Église 12, 61

Jérusalem 11, 15, 23, 25, 27, 29, 31, 49, $52-53,64,91,96-97,118,168,173-$ $180,189-190$

Jésuites 180, 215

Joannes Cerchassus, voir Ğān Balāt 
Jomier, Jacques 132

Jordan, Mark 80

Josaphat 180-191, 215

Joseph ha-Nasi Ferruziel, médecin juif

d'Alphonse VI 88

Joseph Ibn Tsadik, poète juif andalou 87

Joseph, roi de Khazars 128

Jostkleigrewe, Georg 17, 211

Jourdain 21, 24, 92, 94

Juda Halévi, poète juif andalou 16, 84-99, 206

Juda Ibn Giyyat, poète juif andalou $87-88$

Judée 93

Juifs 54, 209; - andalous 88; - d'al-

Andalus 96;- de l'Espagne chrétienne

96; - en Terre sainte 22

Jules II, pape 158

Jupiter 168

Justinien $\mathrm{I}^{\text {er }}$, empereur byzantin 15,38

Kairouan 149

Khanat de la Horde d'or 132

Khanses 131

Khazars 125

Kiev 129, 131

Kimaks 129

König, Daniel 16, 208, 214

Konovalova, Irina 133

Lac de Tibériade 21

Lağğ 98

Lambertin Ramaudon, médecin chrétien 164-166

Laodicée 54

Latins 49-50, 54, 70, 151, 206, 213

Laycus, clerc amalfitain 51

Le Goff, Jacques 212-213

Leder, Stefan 212

León 80

Léon de Bénévent, fondateur du couvent amalfitain du Mont-Athos 50

Léon de Naples, archiprêtre 43-44

Léon IV, empereur byzantin 34

Léon Joseph de Carcassonne, médecin juif 163

Léon le Mathématicien, émissaire byzantin 33

Léon Toscan, traducteur à la cour de Manuel I ${ }^{\mathrm{er}}$ Comnène 38

Léon X, pape 158

Leonardo Fibonacci, mathématicien italien 210
Léonce Makhairas, chroniqueur cypriote 113

Léproseries 164

Leroy-Beaulieu, Paul 48

Levant 131, 192-205; - franc 205;- grec 205

Levantins 198

Levi Ibn al-Tabban 87

Lévi-Provençal, Évariste 128

Lewicki, Tadeusz 129

Liban 92

Lieux saints 20-26, 29, 171, 174, 179;au Caire 114

Ligurie 49

Limoges 60

Littoral syrien 112

Littoraux méditerranéens 136, 139, 193

Liutprand de Crémone 64, 211

Lombardie 129, 132

Lopes de Barros, Maria Filomena 207

Lorenzo Dolfin, neveu de Biagio Dolfin 101

Louis II, empereur carolingien 36

Louis le Pieux, empereur carolingien 42, 124

Lucène $87-88$

Lucques 138

Lusignan, dynastie 53-54

Luzatti, Michele 158

Lydda, église 52

Macédoine 124, 194

Madīnat az-Zahra' 79

Madrasa du sultan mamelouk an-Nāṣir Muhammad 53

Madrid 39

Magdebourg 127

Mağgariyya 125

Maghreb 15

Magyars 125

Mahomet, voir Muhammad

Mahonais, famille de 50

Mahone, famille de la 50

Maïmonide, philosophe juif 158, 162

Majorque 141, 144

Mamelouks 16, 53-54, 100, 102, 106, $111-113,115-119,171-172,210$

Manāf, tribu arabe 98

Manfred I ${ }^{\text {er }}$, roi de Sicile 149

Manichéens 185, 215

Manses 131

Manuel I ${ }^{\mathrm{er}}$ Comnène, empereur byzantin 38 
Manuel Paléologue, empereur byzantin 196, 203-204

Marchands 210;-chrétiens 113;-de Montpellier 201;-occidentaux 119; pisans, génois, vénitiens et catalans 141 ; - vénitiens $100,102,107,111$, 141 ; - des villes méridionales 201

Marche supérieure d'al-Andalus 76, 78

Maréchal de Boucicaut 200

Marğ Rāhit 76

Margrave de Toscane 59

Marie, mère de Jésus 44

Marino Sanuto, géographe de l'Italie 144

Marins 210

Marquisat de Ferrare 132; -

Marquisat de Montferrat 132

Marsa Susa 138

Marseille 12, 17, 131-132, 158-164, 206

Martinez-Gros, Gabriel 98

Martinus Oppaviensis 133

Martyrs de Cordoue 66-68

Marvan Ferrier, médecin juif 160

Marvan, dynastie médicale juive 160

Marx, Karl 12

Masğid al-Harām 176, 179

Mashhad 125

Massif de l'Atlas 142

Massignon 90

Mathieu, évangéliste 51

Matteo Balbo, agent de Charles de Valois 195

Mattheus Balbus, agent de Charles de Valois 195

Mauro d'Amalfi 51

Mauro-Pantaleone, famille de 51

Mauss, Marcel 32

Mayence 127

McCormick, Michael 45-46

Mecia de Viladestes, cartographe 137-138

Mecque, La 85, 176, 179

médecins 143, 157-167; - juifs de Marseille 206

Méditerranée 14-16, 43, 56-57, 71-73, 108, 111, 134-136, 192-195, 200-201, 203, 205, 206, 216; - musulmane 210; - occidentale 15,157 ; - orientale 111 , $119 ;-$ septentrionale 145

Meïr Ibn Kamaniel $87-88$

Menocal, María Rosa 84, 98

Mer Baltique 141-142; - Caspienne 142; - Rouge 94, 100, 104, 106

Mérinides 213

Michael Scot 152
Michel, saint 51

Midi, le 162, 201

Mieszko I ${ }^{\mathrm{er}}$, duc polonais 127

Moines 143

Moïse Ibn Ezra, poète juif andalou 87, 96

Moïse ibn Tibbon, traducteur juif 158

Moïse, prophète israélite 94

Monaco 202

Monastère amalfitain du Mont-Athos 51;de Grotaferrata 41; - du Mont-Cassin 148-149; - de Saint-Michel de l'Herm 184; - de Stoudios 41

Monde arabe 141; - arabo-musulman 17, $205,207,209$; byzantin 33,141 ; - catholique 136, 143-144, 146; - chrétien 62;- latin 206-207; - latino-chrétien 17, 70, 207, 209; - méditerranéen 126, 200;- musulman 14, 29, 122, 143, 206

Mongols 112, 133, 144

Mont Athos 50-51, 190; - Cassin 148; Hermon 91;- Horev 91; - des Oliviers 91;-du Temple 25, 92

Mont-Saint-Michel 214

Mont-Cassin, monastère du 51, 148-149

Montagnes de Transjordanie 27-28

Monte Sant'Angelo 51

Montferrat 132

Montpellier 132, 162-163, 201

Montpelliérains 201-202

Mosquée al-Aqșā 52-53, 168, 173-179; de Cordoue 171, 208; - des Omeyyades de Damas 168-173, 178, 208

Mossé de Palerme, médecin juif 160

Mossé Salves, chirurgien juif 160

Mosson, fils de maître Abraham Bondavin 161-162

Mu'āwiya b. Marwān b. al-Ḥakam, Omeyyade 75

Mudéjares 213

Muğāhid al-'Āmirī, souverain de Denia $65,74,208$

Muhammad I ${ }^{\mathrm{er}}$, émir omeyyade d'alAndalus 76

Muhammad, prophète de l'islam 25-26, $29,62,67,80,147,170$

Muhī ad-Dīn b. Zakī, qāḍī ayyoubide de Jérusalem 175, 177

Muhī ad-Dīn Ibn al-'Arabī, mystique et poète andalou 99

Mūsa b. Mūsa, membre des Banū Qasī 76

Muwalladūn 77-78

Mytilène 54 
Najd 89

Naples 23, 37, 44

Napoléon ${ }^{\text {er }} 12$

Narbonne 60, 131-132

Nasar Chous, compagnon de Janus de Lusignan 115, 117

Nasrides, dynastie 213

Nazareth 53

Nègrepont 54

Némésios d'Émèse, auteur byzantin 38

Nicolas de Grotaferrata, émissaire d'Urban II à Constantinople 40

Nicolas IV, pape 132

Nicolas, saint 51

Nicolò di Malerbi, voir Filippo di Malerbi

Nicolò Dolfin, marchand à Venise 102

Nicopolis 196

Nil occidental, fleuve imaginaire 142

Nil, le 94, 116, 142

Noirs 123

Non-Arabes $62-63,74-78$

Normandie 129

Normands 15, 155

Notker le Bègue, auteur carolingien 43

Nūr ad-Dīn 212

Occident 28-31, 36-37, 41, 44, 47-48, 51, 53, 95-98, 130, 147, 152, 196, 203-204, 207, 214; - chrétien $31,35,37-38,40$, 43-44; - latin 38, 147, 149-150, 156157, 206, 209, 212; - médiéval 212

Occidentaux 28, 41, 48, 53

Omeyyades 76-78, 83, 87, 97-98, 168, 171-172, 178

Ordoño II, roi de León 80

Orgier, famille arlésienne 160

Oriens horribilis $26,29-30$

Orient $15,17,29,48-49,53,90,94-95$, 97-98, 133-134, 147, 152, 192-193; abbasside 40 ; - byzantin $38-40$; - européen 209; latin 52, 66; - méditerranéen 44;- musulman 48, 126

Orientaux 26, 53-54

Orso Dolfin, cousin de Biagio Dolfin 102 104

Orthodoxie malékite 87

Ostiaks 131

Ottomans 144, 196

Otton I ${ }^{\text {er }}$, empereur saxon $37-38,41,126-$ 128,211

Otton II, empereur saxon 37

Otton III, empereur saxon 38

Ourmia, lac de 142
Outre-mer 15, 48-49

Ouvriers persans, indiens, maghrébins et rūms 169

Oviedo 81

Özbeg, Khan de la Horde d'or 144

Padoue 148, 153, 156, 213

Pahlitzsch, Johannes 16, 207

Palais de Bryas 33

Palerme 38, 54, 129, 152, 155, 160

Palerme, dynastie médicale juive 160

Palestine 27

Pantaleone d'Amalfi 51

Paolo, neveu d'Andrea Alpago 154

Paradis 170

Paravicini, Werner 196

Paris, fils de Ğān Balāt 118

Paul Orose, historien romain 123, 127, 133,141

Paulus, saint 28

Pays baltiques 127 ;-communistes 11 ;francs 65 ;-d'islam 98;-des Kimaks 129; - du Levant 198; - musulmans 131 ; - scandinaves 129 ; - slaves 127 ; - socialistes 11

Pays-Bas 196

Pélage de Cordoue $80-83$

Pelayo, Pelagius, voir Pélage

Pèlerins chrétiens à Jérusalem 20-30

Péniel 91

Péninsule Ibérique 58, 74, 76, 78, 80-81, 97, 147, 184, 212

Pentapole 138-139

Pépin le Bref, roi carolingien 43, 124

Péra 54

Pères grecs de l'Église 51

Pero Tafur, voyageur castillan 115

Perrino Vesconte, cartographe génois 139, 142-145

Petachia de Ratisbonne 127

Peuples de l'Orient européen 209

Philippe IV le Bel, roi de France 194-195

Philippe le Grec, agent de Charles de Valois 195

Philippe VI de Valois, roi de France 195, 201

Philippos Marchianos, agent de Charles de Valois 195

Philologues 143

Philosophes 143

Philostorgius 68

Phocée 49-50

Photius 33 
Piero di Malerbi, frère de Filippo di Malerbi 105, 109

Pierre Alphonse, astronome et médecin converti 70, 214

Pierre Damien, religieux italien 44

Pierre Daumas, marchand 166

Pierre de Nonantola, ambassadeur carolingien à Byzance 42

Pierre de Servières, recteur de l'hôpital des pauvres du Christ et du Saint-Esprit 166

Pierre Gaudin, bachelier en médecine 167

Pierre ${ }^{\text {er }}$ de Lusignan, roi de Chypre 112 , 196

Pierre II de Lusignan, roi de Chypre 53

Pietro Vesconte, cartographe génois 139 143,145

Pisans 74,133

Pise 38, 74, 132-133, 137, 150, 202

Plaisance (Piacenza) 54

Platon 158

Poivert, Michel 14

Pologne 127, 129

Populations fino-ougriennes 131

Port du Caire 114

Port royal d'Aigues-Mortes 201

Portal, Félix 163

Ports du Delta 100; - syriens 111

Portugal 207

Prague 127

Prawer, Joshua 48

Prêtres éthiopiens 210

Princes français 194, 200

Principauté d'Antioche 150

Prisonniers francs 178; - de guerre 111

Proche-Orient 26, 131-132, 168

Prostituées musulmanes 116

Provence 129, 132, 157, 161, 165-166

Proventsa 162

Prusse 196

Prussiens 127

Ptolémaïs 138

Ptolémée, Claude 39, 122-123, 129, 141, $143,151,158$

Puissances occidentales 204

Pyrénées 134

Qāyitbāy, sultan mamelouk 118

Rabelais, François 158

Radāniyya, groupe de juifs 126

Raguel 80

Rainier Grimaldi, amiral de France 195

Ramla, église 52
Ramón de Moncada, ambassadeur de la couronne d'Aragon 38

Rašīd ad-Dīn, historien persan 133

Raymond d'Aguilers, chroniqueur des croisades 66

Raymond Pibarot, médecin chrétien 164 166

Razès, voir Abū Bakr b. Zakariyā' ar-Rāzī

Régions baltiques 129

Renaud de Grenier, comte de Sidon 61

République démocratique allemande 11

Républiques maritimes italiennes 193

Rhazès, voir Abū Bakr b. Zakariyā’ ar-Rāzī

Rhénanie 126

Rhodes 54

Ricoldo da Monte Croce, prêcheur dominicain 29,60

Riley-Smith, Jonathan 49

Rivages méditerranéens 136, 138-139, 206-207

Riverains méridionaux et orientaux de la Méditerranée 192

Riviere ligures 49,54

Rodolphe d'Ems 191

Roger II, roi normand de Sicile 128-129, 151

Roi d'Aragon 214; - de France 132

Rois d'Arménie 194;-d'Italie 211;-de Serbie 194

Romains 41, 69

Romanie 49, 194

Rome 23, 34, 51, 124-125, 133, 158

Rosette, port militaire mamelouk 102

Rotonde de l'Anastasis 52

Rouen 127

Royaume d'Angleterre 196;-d'Aragon 196; - castillan 213; - de Chypre 112, 207, 213; - franc de Jérusalem 48; - de France 193, 196-198; - grec de Trébizonde 132;-d'Israël 95; - de Judée 93 ; - des Lusignan 54 ; - nordique 128 ; - des Pays-Bas 196

Royaumes de l'Europe latine 200;-dits >germaniques< 15 ; -d'Occident 204; de Taifas 62, 65-66, 86-87, 89, 98, 208

Ruchaud, Elisabeth 15, 209

Rūm 34-35, 122

Rūmī (= Byzantin) 75

Rūs/Russes 125, 127-129

Russie 129

Šaddād b. 'Amr, Arabe de la tribu de 'Abs 77 
Safed 137

Sainte-Marie-des-Teutoniques, église 52

Sainte-Sophie, église 43

Saint-Esprit 51

Saint-Jean-d'Acre 95, 112

Saint-Malo 127

Saint-Marc, église 51

Saint-Martial de Limoges 60

Saint-Paul-hors-les-murs, église 51

Saint-Sépulcre 21, 26, 52

Saints catholiques $180 ;$ - chrétiens 185

Saladin, voir Șalāh ad-Dīn

Șalāḥ ad-Dīn, sultan ayyoubide 11,168 , 174-175, 177-178

Salerne 38,51

Saline 137

Salomon, roi israélite 84,170

Salomon de Palerme, médecin juif 160

Salomonet Avigdor, médecin juif 161

Salon-de-Provence 161

Salvet de Bourgneuf, élève de Sarah de Saint-Gilles 161

Samuel Ha Nagid, poète juif andalou 84, 86,89

Samuel de Marseille, traducteur 158

Samuel de Palerme, médecin juif 160

Sancho I ${ }^{\mathrm{er}}$, roi de León 81

Saragosse 76, 87

Sarah de Saint-Gilles, médecin juive de Marseille 161

Saray 144

Sardaigne 74, 159, 208

sarracenus 24

Sarrasins 24, 29, 41, 195

Satan 93

Scandinaves 126

Scandinavie 123, 126, 207

Schiffauer, Werner 56-57

Scythes 123

Seigneurs féodaux 193

Seljouks 15, 171

Sénac, Philippe 124

Sénéchal de Beaucaire 201

Sept Dormants 34

Serbie 194

Serge, abbé du couvent Sainte-Marie des Amalfitains 51

Séville 87-88, 123-124, 214

Seyfullah, jeune islamiste allemand 5657,69

Shatzmiller, Joseph 159-161

Shem Tob ben Isaac de Tortose, médecin juif 161
Sibon, Juliette 17, 206

Sicile 23, 38-39, 66-67, 124, 129, 132, $134,148,151-153,155,213$

Signoria 118

Siloé 92

Simone Vignoso, amiral génois 50

Sinaï 136

Sion 93-96

Sivan, Emmanuel 97

Slaves 122-123, 125-126, 209

Smyrne 196

Soest 127

Soldats égyptiens 116

Soravia, Bruna 86

Sot, Michel 39-40

Souverains normands 155 ; - perses 63

Stouff, Louis 157

Šuhayd b. 'Īsā b. Šuhayd b. al-Waḍdạh, client omeyyade en al-Andalus 75

Suhrāb, géographe persan 123

Sulaymān, fils de l'émir 'Abd arRahmān I ${ }^{\text {er }} 98$

Sultanat mamelouk 111-112

Šu'ūbiyya 77

Syrie 15, 24, 33, 54, 97-98, 112, 126-127, $133,154-155,168,170,175,212-213$

Syrie-Palestine 53, 97

Tābit b. Qurra, savant sabéen 51

Tabriz 144

Tagir 210

Taïfa de Denia 208

Tamerlan, fondateur de la dynastie des Timourides 113

Taqī ad-Dīn, neveu de Șalāh ad-Dīn 174

Tarasios 34

Tatars 53, 132

Tayyi', tribu arabe 77

Tell Muzan 125

Temple 92

Templiers 66, 173

Templum domini 52, 173; - salomonis 52,173

Terés, Elias 98

Teresa, épouse de Sancho ${ }^{\text {er }} 81$

Ternovo 133

Terre d'islam 31,130 ; - promise 22 ; sainte $20-22,24,26-27,49,53-54$, 92-93, 95-97

Théoctiste d'Adrianople, archevêque 195 Théophile, empereur byzantin 33

Thessalonique 195

Thibaut de Chepoy, noble champenois 194 
Thietmar, magistère 27-29

Thomas, fils de Ğān Balāt 118

Thrace 124, 194

Tibbonides, voir Ibn Tibbon

Tigre 141

Tigre, fleuve 144

Tolan, John 71

Tolède $51,81,88,143,148,150,153$, 206, 213

Tortose 129, 161

Tortose, cathédrale 52

Toscane 129, 133

Touati, Houari 99

Toulouse 132

Tourfan, oase de $185-186$

Tournemire, chancelier de l'université de Montpellier 163

Transjordanie 28

Trébizonde 129

Tribunal angevin à Marseille 163

Tribus nomades 148;- polonaises 127

Tripoli 54

Troupes chypriotes 53,117; - mameloukes 117

Tudèle 76,87

Tunisie 195

Turcopoles 66,68

Turcs 122-123, 196

Turquie 56

Turrush 78

Ukraine 131

'Ulamā' 111

Ulfila, évêque et missionnaire goth $68-70$

'Ulwān, 'Abd Allāh Nāṣih 11

'Umar b. al-Hatțāab, deuxième calife de l'islam 170, 175

'Umāra b. Hamza, émissaire abbasside 42, 47,126

Umayya b. 'Īsā b. Šuhayd, client omeyyade en al-Andalus 75-78, 83

Universitaires arabisants 207; - médiévistes 207

Université 160;-de Montpellier 163;de Padoue 153

Universités latines 150

Urbain II, pape 40

Usāma b. Munqid, noble syrien $61,64-65$

Valachie 133

Valdejunquera 80
Vallée de la Volga 130; - du Jourdain 52

Valois 144

Van, lac de 142

Vandales 15

Vascons 209

Vatican 143

Veit, Raphaela 17, 213

Venayre, Sylvain 84

Vendée 184

Vénétie 129

Venise 16, 51, 101-106, 108, 111, 118, 131-133, 141-145, 148, 153-157, 194, 202, 213

Vénitiens 100, 103-104, 106, 107

Vérone 157

Vice-roi de Damas 118

Victor III, pape 148

Vidonet Bonisac, juif de Marseille 163

Villes littorales syriennes 111

Vincent de Beauvais, encyclopédiste français 184

Visigoths 15

Vital de Lunel, chirurgien juif 164-165

Vladimir, ville russe 129

Voguls 131

Voie Egnatia 125

Volga $125,128,130-133,141$

walad zinā'/bâtard 116

Wālid b. Ġānim, șāhịb al-madīna à Cordoue 76

Wibald de Stavelot, abbé de Stavelot, Mont-Cassin et Corvey 41

Widukind de Corvey, chroniqueur saxon 41

Willibald, évêque d'Eichstätt 23-24, 29

Xe Services, entreprise de sécurité 200

Yāqūt al-Hamawī, géographe 131

Yemenites 75

Yūnān 34

Zaccaria, Bennedetto 49

Zaccaria, Manuel 49

Zankides, dynastie 97

Ziyādat Allāh b. al-Ag̉lab, souverain de

l'Ifrīqiya aghlabide 59

Zouache, Abbès 212

Zuan Cercasso, voir Ğān Balāt 